\title{
Implementing the 3E assessment model of sustainable devel- opment to investigate coastal pollution management: using PET recycling (bottle-to-fiber) as a case study
}

$1 \quad$ Affiliation 1; shuhui@mail.ntpu.edu.tw

2 Affiliation 2; oct1008506@gmail.com

* Correspondence: Institute of Natural Resource Management, National Taipei University. 151, University Rd., San Shia Dist., New Taipei City 237, Taiwan . shuhui@mail.ntpu.edu.tw ; Tel:+886926376322

Citation: Hung, S.H.; Wang, Y.T., 2022, Implementing the 3E assessment model of sustainable development to investigate coastal pollution management: using PET recycling (bottle-to-fiber) as a case study. SUPTM 2022 conference proceedings sciforum-054480.

https://doi.org/10.31428/10317/10604 Publisher's Note: UPCT and Sciforum stays neutral with regard to jurisdictional claims in published maps and institutional affiliations.

Copyright: (c) 2022 by the authors. Submitted for possible open access publication under the terms and conditions of the Creative Commons Attribution (CC BY) license (https://creativecommons.org/license s/by/4.0/).

\begin{abstract}
Recently, plastic pollution of the ocean has been garnering increasing attention. The United Nations considers the problem as a major issue, and the UN Environment Programme (UNEP) has launched a global "Clean Ocean" campaign. An estimated 51 trillion plastic particles can be found in our oceans, and the pollution has caused plastics to enter the food chain. This study investigates the life cycle of recycling waste PET (polyethylene terephthalate) bottles in the ocean to the regeneration of recycled raw materials in the process of producing blankets made from such materials. First, the activity data of the relevant literature was collected, and the life cycle assessment software Open LCA was used as the assessment tool. We assume that the functional unit is 1 $\mathrm{kg}$ of recycled PET bottles. Secondly, with the ILCD 2011 Midpoint impact assessment method for environmental impact analysis, we identify the impact of pollutants generated during the recycling process on the environment as follows: Photochemical ozone formation 7872256.41218/ kg NMVOC eq; Freshwater ecotoxicity 240566129.10051/ CTUe; Human toxicity, cancer effects 120.28305/ CTUh; Human toxicity, non-cancer effects 1.53496/ CTUh. Finally, we conduct risk assessment using the 3E (Engineering, Environment and Economic) assessment model, and propose an overall recovery treatment optimization assessment model.
\end{abstract}

Keywords: PET bottle recycling ; blanket production ; life cycle assessment ; environmental impact ; 3E

\section{Introduction}

According to research statistics, it is estimated that there will be more waste than fish in the ocean in 2050. The mother of the earth, the ocean, occupies $70 \%$ of the earth's surface area. The health of the ocean is closely related to human life. In addition to providing abundant resources, it also provides ecological functions such as biodiversity and plays a very important role in the environment. Due to human activities, about 8 million tons of plastic flows into the ocean every year, causing 100,000 marine animals and at least one million seabirds to die from plastic waste pollution. Such pollution not only causes irreparable damage to water quality and habitat, but also brings risks to human health through the food chain [1,2]. At present, the actions of countries on the treatment of marine debris are mainly focused on cleaning up; the process is not only costly and laborious, but also cannot really eliminate the pollution.

This study examines whether PET plastic bottles can be subjected to the four major steps of ISO 14040 and ISO 14044 life cycle assessment methods to generate the bottles' renewable value and create a circular economy, instead of becoming disposable pack- 
aging and ultimately becoming useless garbage that threatens the environment.

\section{Area of Study}

This study undertakes a life cycle assessment of converting used PET bottles into recycled raw materials used in the process of producing fabric blankets made from recycled materials. The cost of energy and resources is studied, as well as the judgments, trends and suggestions of the results after the analysis of the assessment software. Finally, 3E (Engineering, Environment and Economic) risk assessment analysis is conducted, and an optimal assessment model for the overall recycling process is proposed.

\section{Methodology}

Life cycle assessment refers to the collection and analysis of process data in different states such as the acquisition, manufacturing, distribution, sale, and final use of raw materials through products or services. In the life cycle assessment method, there are mainly three types of route assessment: (1) cradle to grave [3, 4], (2) cradle to cradle [5], (3) gate to gate [6]. This study adopts (3) door-to-door approach for life cycle assessment.

Through the life cycle assessment methods of ISO 14040 and ISO 14044, the bottle to fiber life cycle assessment of PET bottles is carried out in four steps: (1) Goal and scope definition (2) Inventory analysis (3) Impact Assessment (4) Interpretation of Life Cycle Results

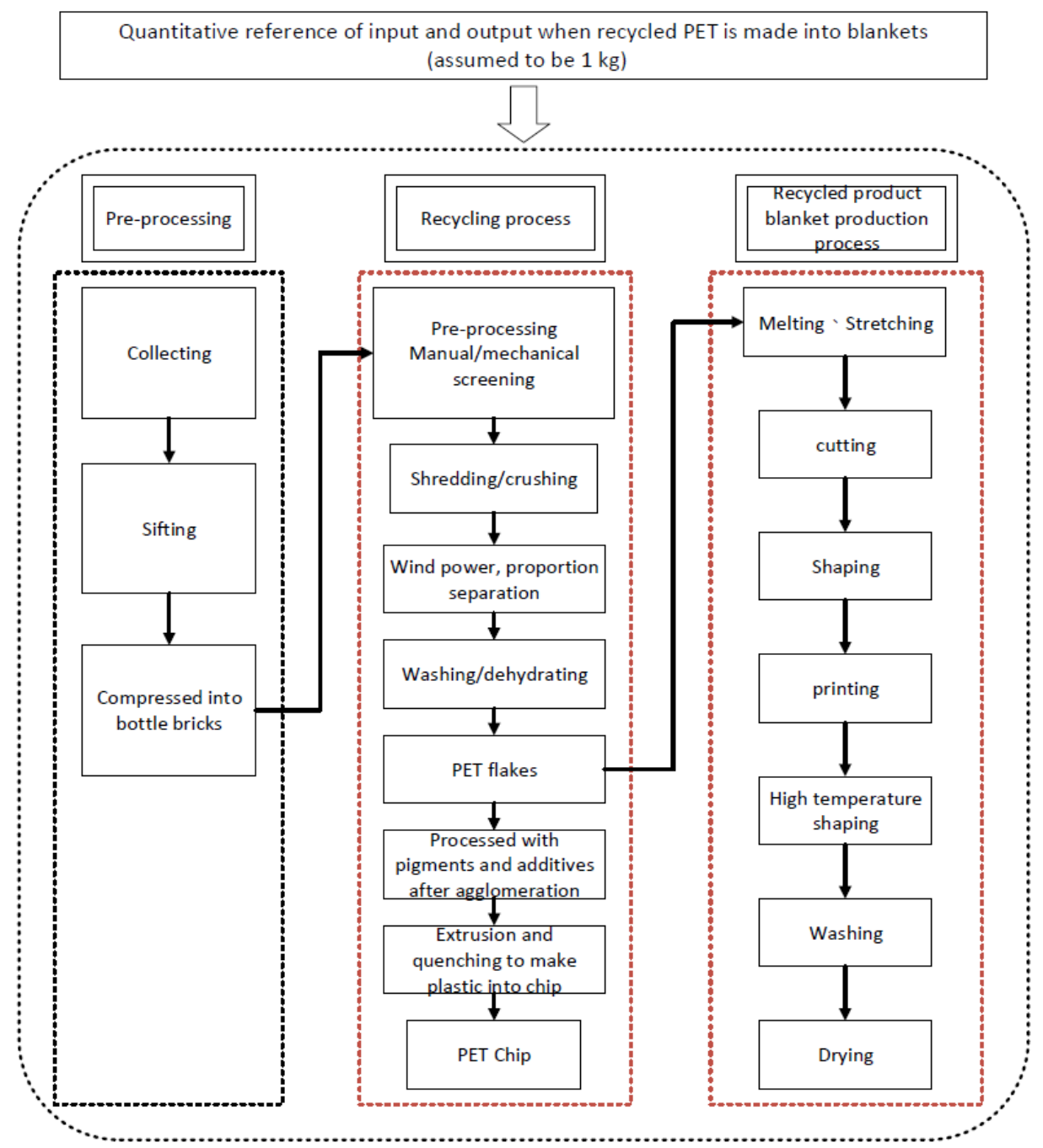

Figure 1. System boundary of LCA. 
In this study, the free tool OpenLCA developed by Green Delta is used for life cycle assessment analysis. Life cycle impact assessment analyzes the negative impacts in the defined categories, including various oriented project assessments such as human health, ecological environmental impact, and resource use [5]. This study adopts the European Union's ILCD 2011 Midpoint methodology, and analyzes four of them.

The Figure 1 is the system boundary of the study, which applied the door-to-door approach for life cycle assessment in the case.

\section{Result}

Calculated by the ILCD 2011 midpoint methodology and combined with Normalization and weight set: EU27 2010, equal weighting is the EU's 2010 average weight (average value assumed by each population), using standardized factors, population and other data as the standard; the results are shown in Table 1. As shown, the impact results of PET plastic bottles recycled in units of $1 \mathrm{~kg}$ and then made into fiber blankets for each category are as follows: four items are selected from the 16 impact assessment items that are most relevant to human life. The four items are: 1) human toxicity - non-cancer effects, 2) human toxicity - cancer effects, 3) climate change indicated by photochemical ozone formation, and 4) freshwater ecotoxicity.

The impact assessment obtained in freshwater ecotoxicity is 240566129.10051 CTUe. The impact assessment obtained for human toxicity - non-cancer effects 1.53496/ CTUh, meaning that this process may cause 1.5 people to have non-cancer diseases; for human toxicity, cancer effects, it is 120.28305 / CTUh, meaning that this process may cause 120 people cancerous diseases. The photochemical ozone formation is $7872256.41218 / \mathrm{kg}$ NMVOC eq.

In general, the impact of the PET bottle recycling process into fabric blankets on the environment and humans in the process is greater than the carbon dioxide emissions in the "climate change" project.

After the final weight conversion of the assessment results in Figure 2, a unified environmental impact score can be obtained; the final environmental impact score obtained in this study can be seen that the total impact of human toxicity - cancer effects on the

Table 1. Impact analysis: ICLD 2011 Midpoint+.

\begin{tabular}{ccc}
\hline Impact category & Result & Reference unit \\
\hline Acidification & 0.38209 & molc H+ eq \\
Climate change & 54.49934 & $\mathrm{~kg} \mathrm{CO}$ eq \\
\hline Freshwater ecotoxicity & 240566129.10051 & CTUe \\
Freshwater eutrophication & 0.00103 & $\mathrm{~kg} \mathrm{P} \mathrm{eq}$ \\
Human toxicity, cancer effects & 120.28305 & CTUh \\
Human toxicity, non-cancer effects & 1.53496 & CTUh \\
Ionizing radiation E (interim) & 0.00006 & CTUe \\
Ionizing radiation HH & 4.83770 & $\mathrm{kBq}$ U235 eq \\
Land use & 0.47703 & $\mathrm{~kg} \mathrm{C} \mathrm{deficit}$ \\
Marine eutrophication & 0.07161 & $\mathrm{~kg} \mathrm{~N} \mathrm{eq}$ \\
Mineral, fossil \& ren resource depletion & 0.00068 & $\mathrm{~kg} \mathrm{Sb} \mathrm{eq}$ \\
Ozone depletion & 0.0000034 & $\mathrm{~kg} \mathrm{CFC-11} \mathrm{eq}$ \\
Particulate matter & 0.01537 & $\mathrm{~kg} \mathrm{PM2.5} \mathrm{eq}$ \\
Photochemical ozone formation & 7872256.41218 & $\mathrm{~kg} \mathrm{NMVOC} \mathrm{eq}$ \\
Terrestrial eutrophication & 0.82981 & $\mathrm{molc} \mathrm{N} \mathrm{eq}$ \\
Water resource depletion & 0.03150 & $\mathrm{~m} 3$ water eq \\
\hline
\end{tabular}


environment is up to $2.17325 \mathrm{E} 5 \mathrm{Pt}$, The second is photochemical ozone formation at $1.65566 \mathrm{E} 4 \mathrm{Pt}$; the third is freshwater ecotoxicity at $1835.06603 \mathrm{Pt}$; and the fourth is human toxicity - non-carcinogenic effects at $191.9903 \mathrm{Pt}$.

If the risk score is defined based on the 16 impact scores produced by OpenLCA, as shown in Table 2, the risk can be divided into three levels, namely high, medium, and low; 4 of the 16 items are considered high risks, of which 12 are low risk. In terms of proportion, high risk accounts for $25 \%$ and low risk accounts for $75 \%$. The result shows that the process technology of recycling PET plastic bottles not only reduces the impact of waste on the environment, but also achieves recycling. The purpose of economy is to achieve 3E (environment, economy, engineering) visions at three different levels.

Table 2. Risk Assessment Level

\begin{tabular}{cc}
\hline Risk Level & Standart \\
\hline High & $>1$ \\
Middle & $=1$ \\
Low & $<1$ \\
\hline
\end{tabular}

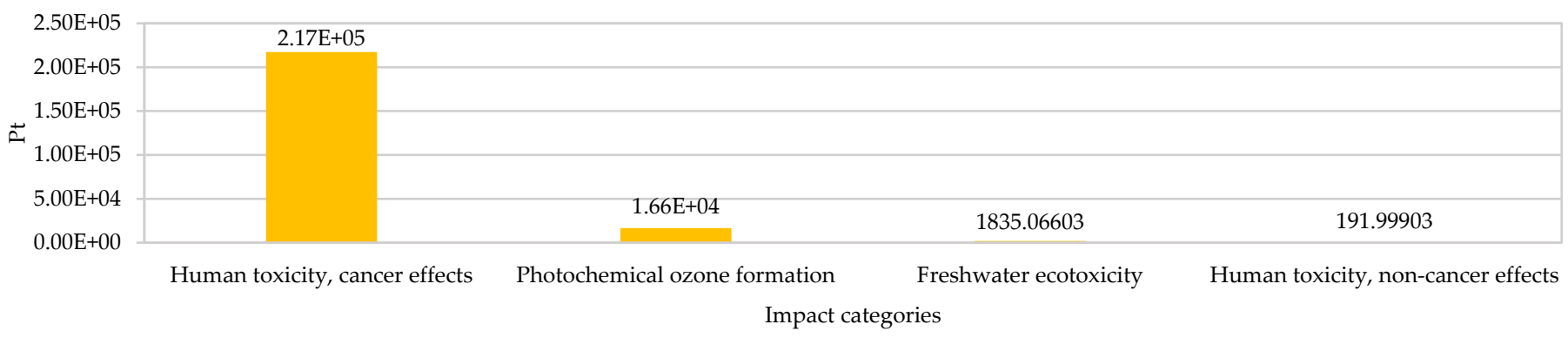

Figure 2. Normalization and weight of Singore score.

\section{Conclusion}

This study explores the current status of related plastic recycling abroad, and uses life cycle assessment methods to find out the environmental impact of PET plastic recycling and plastic remaking into microfibers for fabric blankets. Using these findings, we can improve the efficiency of recyclable resource use. It can also achieve the purpose of a circular economy while integrating resources efficiently, as well as optimize the process of energy resource consumption analysis.

\section{References}

1. Chen, Y., et al., Life cycle assessment of end-of-life treatments of waste plastics in China. Resources, Conservation and Recycling, 2019. 146: p. 348-357. https://doi.org/10.1016/j.resconrec.2019.03.011

2. Chu, J., et al., Dynamic flows of polyethylene terephthalate (PET) plastic in China. Waste Manag, 2021. 124: p. $273-282$. https://doi.org/10.1016/j.wasman.2021.01.035

3. L'Abbate, P., et al., Environmental analysis of polyester fabric for ticking. Journal of Cleaner Production, 2018. 172: p. 735-742. https://doi.org/10.1016/j.jclepro.2017.10.045

4. Sazdovski, I., A. Bala, and I.P.P. Fullana, Linking LCA literature with circular economy value creation: A review on beverage packaging. Sci Total Environ, 2021. 771: p. 145322. https://doi.org/10.1016/j.scitotenv.2021.145322

5. Marathe, K.V., K.R. Chavan, and P. Nakhate, 8 - Life Cycle Assessment (LCA) of PET Bottles, in Recycling of Polyethylene Terephthalate Bottles, S. Thomas, et al., Editors. 2019, William Andrew Publishing. p. 149-168. https://doi.org/10.1016/B978-0-12-811361-5.00008-0 